\title{
Cerebellar Synaptopathy in Streptozotocin-Induced Diabetic Rats
}

\author{
Sinaptopatía Cerebelosa en Ratas Diabéticas Inducidas por Estreptozotocina
}

Apichaya Niyomchan; Sirinush Sricharoenvej; Passara Lanlua \& Sani Baimai

NIYOMCHAN, A.; SRICHAROENVEJ, S.; LANLUA, P. \& BAIMAI, S. Cerebellar synaptopathy in streptozotocin-induced diabetic rats. Int. J. Morphol., 37(1):28-35, 2019.

SUMMARY: There is an increasing amount of evidence that supports the diabetic complications of the central nervous system structure and function. The cerebellum, which is one of the primary structure derived from the hindbrain, plays an important role in motor control, motor coordination, and non-motor functions, such as cognitive processing. The synapse is a critical structure that regulates neuronal communication, and well-defined afferent and efferent fibre connections in the cerebellum help in maintaining the proper working order. Thus, the present study sought to investigate the long-term effects of diabetes-induced synaptopathy in the cerebellum, using both histological and ultrastructural studies. Twenty Sprague-Dawley male rats were divided randomly into control and diabetic groups, and diabetes was then induced through a single intraperitoneal injection of streptozotocin (60 mg/kg body weight). Six month later, the rats were sacrificed and the cerebellum was removed. Light and electron microscopic examinations showed a degeneration of Purkinje cells (Neuron purkinjense) with shrunken cells, pyknotic nuclei, and synaptopathy, including the reduction in synapse density, number of synaptic vesicles, and maturation of synapses in the molecular layer of diabetic cerebellum. The disruptions in synaptic profiles, which observed in the diabetic condition, could be related to cerebellar dysfunction, thus leading to the defects in coordinated movement, balance, as well as cognitive learning and memory.

KEY WORDS: Cerebellum; Diabetes mellitus; Streptozotocin; Synaptopathy.

\section{INTRODUCTION}

Diabetes mellitus is one of the most common and chronic metabolic diseases and is characterized by insulin deficiency or resistance and hyperglycemia, which is an elevated levels of sugar in the blood (American Diabetes Association, 2011). Chronic complications of diabetes include all parts of the body that lie both within and without the central nervous system (CNS). The brain, the largest portion of the CNS, is a probably target and also a source of insulin. Pancreatic insulin in the plasma reaches the brain through cerebrospinal fluid and/or the transendothelial transport. This then, goes into the interstitial fluid around the neurons and glial cells (Gray et al., 2014). Local insulin in the brain is released by a subpopulation of neurons in the cerebral cortex and neural progenitor cells within the hippocampus (Csajbók \& Tamás, 2016). Insulin signaling in the brain not only regulates food intake and glucose homeostasis but is also involved in general neuronal survival, synaptic plasticity and cognitive function (Duarte et al., 2012). The alterations in an insulin action induced by diabetes can thus lead to brain damage and neurodegenerative disorder.
One particular brain region where high expression of insulin receptor has been found is the cerebellar cortex (Kleinridders et al., 2014). The cerebellum's anatomical position is located behind the cerebrum and atop the brain stem (pons and medulla oblongata). Besides motor functions, which includes the maintaining of balance and coordinating movements, the cerebellum is also associated with learning and memory (Tedesco et al., 2011). The adverse effects of diabetes on cerebellum have thus been reported in both diabetic patients and animal models. Diffusion tensor imaging was performed for white matter pathway analysis, and it revealed decreased anatomical connections in the cerebellar cortex and cerebro-cerebellar circuits of type 2 diabetic patients (Fang et al., 2017). Ultrastructural changes and an increase in apoptotic activity was found in the type 1 diabetic rats (Hernández-Fonseca et al., 2009). Gestational diabetes induces a loss in number and size of the Purkinje cells (Neuron purkinjense) and the granular cells in the rat cerebellum in early postnatal life (Razi et al., 2015). Furthermore, maternal diabetes appeared to affect the 
synaptogenesis in the developing cerebellum of the offspring (Hami et al., 2016).

Although there are several studies that discuss the effects of diabetes on the cerebellum in both a structural and biochemical analysis, diabetic effects on synaptic number and synapse maturity have not yet been demonstrated in the diabetic rat. Considering the alterations of synapses within the downregulation of circuit function can lead to an interference with the important roles of the cerebellum, as such, this experimental study aims to investigate the impact of long-term diabetes on cerebellar synaptic profiles, with the main focus being on the density and maturity of synapses in streptozotocin (STZ) induced diabetic rats.

\section{MATERIAL AND METHOD}

Animal handing. All animal experiments were performed in compliance with the Guide for the Care and Use of Laboratory Animals. The approval of the ethics committee of Siriraj Laboratory Animal Research and Care Center, Mahidol University (COA No. 009/2561) was obtained prior to the study. Twenty adult male Sprague-Dawley rats (5-8 week old) weighing between 200-270 g were used. The rats were housed each in a cage with a constant temperature $(23 \pm 2$ ${ }^{\circ} \mathrm{C}$ ), had a $12 \mathrm{~h}$ light-dark cycle and free access to the standard rat pellet diet and distilled water. Following a week of acclimatization, the rats were randomly assigned to control and diabetic groups, with each group consisting of 10 rats.

Induction of diabetes. In the diabetic group, diabetes was induced by a single intraperitoneal injection of freshly dissolved STZ in a $0.1 \mathrm{M}$ citrate buffer $(\mathrm{pH} 4.5)$ at a dosage of $60 \mathrm{mg} / \mathrm{kg}$ body weight in overnight ( $12 \mathrm{~h}$ ) fasting animals. The control animals were injected with the vehicle alone. Diabetes was verified at $72 \mathrm{~h}$ after injection of the STZ through an assessment of blood glucose levels in blood samples obtained from the tail vein, using blood glucose monitoring system (Lifescan, Milpitas, CA, USA). Rats that had fasting blood glucose levels of above $300 \mathrm{mg} / \mathrm{dL}$ were accepted as diabetes mellitus. To confirm the presence of normoglycemia in control rats, their blood glucose levels were evaluated at the same time as the diabetic group. Diabetic rats were kept for 6 months, to allow the development of long-term diabetes and to observe the manifestation of the chronic effects.

Biochemical and clinical assays. The animal's body weight and urine glucose levels for each overnight fasting rats in both groups were recorded daily. The positive urine glucose was monitored using Diabur-Test 5000 glucose urine test strips (Roche Ltd., Berlin, Germany). The colour scales indicated the amount of glucose present in the urine and blood glucose levels were analysed again by glucometer just prior to the sacrifice. The clinical behaviour was also observed during the entire duration of the experiment.

Light and electron microscopy. At the end of the experiment, animals were anesthetized through halothane inhalation. They were sacrificed by transcardial perfusion, with $0.9 \% \mathrm{NaCl}$ solution to wash out the blood, followed by the Bouin's solution to preserve the tissues for conventional light microscopic and histological study. For electron microscopic study, in order to allow the analysis of the ultrastructure, the animals were perfused with $0.1 \mathrm{M}$ of phosphate buffer solution (PBS) and fixed with $2.5 \%$ glutaraldehyde in $0.1 \mathrm{M}$ PBS. After removal of the brain, the cerebellum from both control $(n=4)$ and diabetic $(n=4)$ rats were cut in the sagittal plane through the middle of the vermis. Next, the cerebellar tissues were routinely processed for light microscopy through standard histological methods, and the sections $(6 \mu \mathrm{m})$ were stained with hematoxylin and eosin to be captured by an Olympus Bx43 microscope and DP73 digital camera that was attached to CellSens Standard software (Olympus Optical, Co. LTD, Japan). The cerebellar tissues for electron microscopy (six rats in each group) were chopped in order to obtain smaller pieces of approximately 1 $\mathrm{mm}^{2}$ from the apex of Larsell's lobule VIa, which was located just caudal of the distinct primary fissure. Samples were postfixed in osmium textroxide, dehydrated in graded alcohol solutions, infiltrated with propylene oxide and embedded in Aradite 502 resin. One $\mu \mathrm{m}$ thick section that was stained with toluidine blue was examined under a light microscope (Axiostar plus, Jena, Germany) to confirm all layers of the cerebellar samples. Next, serial ultrathin sections $(60 \mathrm{~nm})$ were prepared, and were double-stained with uranyl acetate and lead citrate, and evaluated under a JEM-1230 transmission electron microscope (Jeol LTD, Akishima, Japan).

Morphometric analysis. Purkinje cell density was measured from low magnification images (10X objective) of 50 separate fields per each group in the apex of cerebellar lobules. The images were taken for every 5 sections of the cerebellum, to avoid over sampling the same Purkinje cells. The amount of Purkinje cells was reported as Purkinje cell number per $350,000 \mu \mathrm{m}^{2}$ area of the cerebellum.

The synaptic density was counted at 50 random areas from the cerebellar molecular layer of each group through the use of 12,000X magnification. Images were taken for every 10 ultra-thin section to circumvent an issue where the same synapse was counted. The synaptic density was reported as the number of synapse per $110 \mu \mathrm{m}^{2}$ area of molecular layer. 
For synaptic maturity, we selected the synaptic profiles contained with the presynaptic area, clustered synaptic vesicles, and postsynaptic area and imaged under 80,000X magnification for analysis (50 synapses for each group). The results were expressed as a maturation index that was calculated by the following formula:

$$
\text { Maturation index }=(\mathrm{Ac} / \mathrm{At}) \mathrm{x} 100
$$

Where the Ac was an area occupied by clustered synaptic vesicles and At indicated the area of the presynaptic terminal, respectively.

The area of the presynaptic terminal and area occupied by clustered synaptic vesicles were calculated using the UTHSCSA ImageTool 3.0 (University of Texas Health Science Center in San Antonio, San Antonio, USA).

Statistical analysis. Data were analysed using a software program called PASW statistics version 18.0 (SPSS Inc., Chicago, IL, USA). Firstly, the distribution normality of the sample was evaluated through the use of the KolmogorovSmirnov test. All data in this study sufficiently met normal distribution. Thus, the comparisons between two independent groups were made by the Independent-Samples T test. The results were determined in a confidence interval of $95 \%$. The level of significance was set at $\mathrm{p}<0.0001$ and the data was presented as the mean \pm standard error of mean (SEM).

\section{RESULTS}

Diabetes induces weight loss, hyperglycemia, and glucosuria. The biochemical parameters at month 6 , when the animals were sacrificed, is depicted in Table I. A decrease in the final body weight and an elevated blood glucose concentration were observed in the diabetic rats, when compared to their control counterparts. Diabetic rats also contained higher levels of sugar in the urine, which was indicated by a dark green colour urine dipstick (>500 mg/ $\mathrm{dL}$ ). Moreover, the clinical symptoms of diabetes, such as an increase in hunger (polyphagia), thirst (polydipsia) and urine frequency (polyuria), were exhibited in the STZ diabetic rats.
Diabetes reduces Purkinje cell density. The use of light microscopy displayed the histological appearances of the rat cerebellum in the sagittal plane of the vermis (Fig. 1A) that consisted of ten different lobules separated by fissures, in accordance with Larsell's schema (Larsell, 1952). At a high magnification (Fig. 1B), the cerebellar cortex was composed of three distinct layers: the molecular layer, the Purkinje layer and granular layer, respectively, from the outermost to innermost layers. The molecular layer lay directly below the pia mater and consisted mainly of neuropil, the area between the cell bodies of neurons, which was comprised of the neuronal processes, synapses and microvasculatures. Few neurons, including the stellate and basket cells, were located in this layer. Stellate cells lay in the outer two thirds of the molecular layer, while the basket cells were located in the inner third of this layer. Their cell bodies were relatively close, or within the Purkinje cell layer (Stratum purkinjense). The middle narrow zone was a single row of the Purkinje cell layer. It was comprised of the cell bodies of the Purkinje cells, a giant pear-shaped cell consisting of a large round vesicular nucleus with a prominent nucleolus. The innermost layer of the cerebellar cortex was the granular layer which was densely packed with granule cells and few Golgi cells, as the ration was one Golgi cell to every several hundred granule cells. The granule cells were small, darkstaining nuclei and scantly cytoplasm, whereas the Golgi cell was large, irregular cell body with an abundance in cytoplasm and was just below the Purkinje cell layer.

In the diabetic group, some Purkinje cells were shrunken with the pyknotic nuclei (Fig. 2A), suggesting apoptotic cell death. Furthermore, the number of Purkinje cells in the cerebellar section of the diabetic rat was lower than that in the control group, and this was confirmed by the statistical analysis of Purkinje cell density demonstrating a significant reduction in the number of Purkinje cells, reducing from $21.00 \pm 0.52$ cells in the control group to $13.98 \pm 0.54$ cells in the diabetic group (Fig. 2B).

Diabetes decreases synapse density, number of synaptic vesicles, and synapse maturation. To further address the question regarding a decrease in the Purkinje cell number, as seen in the diabetes, and whether it was attributable to diminished synapse density, we performed ultrastructural studies of the synapses, using transmission electron

Table I. Biochemical parameters at the end of the experiment.

\begin{tabular}{lcc}
\hline Parameters & Control $(\mathrm{n}=10)$ & Diabetes $(\mathrm{n}=10)$ \\
\hline Body weight $(\mathrm{g})$ & $431.4 \pm 18.94$ & $240.0 \pm 4.89^{*}$ \\
Blood glucose $(\mathrm{mg} / \mathrm{dL})$ & $121.9 \pm 6.76$ & $478.8 \pm 16.17^{*}$ \\
Urine glucose & - & + \\
\hline
\end{tabular}

$* \mathrm{p}<0.0001$ versus control 

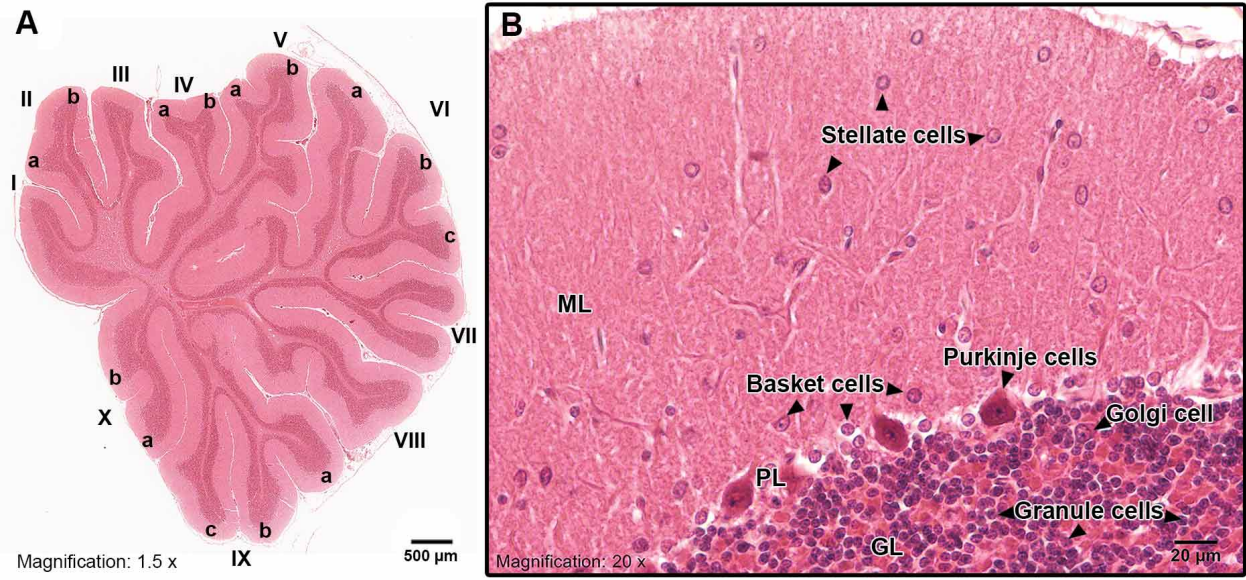

Fig. 1. Lobules and cortical layers of the normal rat cerebellum. (A) Sagittal histological section of the vermis showing ten lobules (anterior to posterior), according to Larsell's schema (I-X) with their subfolia (a, b, c). (B) An enlargement of the cerebellar cortex, which demonstrates the outer layer or molecular layer (ML). This consists of the stellate cells in the superficial part and the basket cells in the deeper region, near the Purkinje cells, with the middle layer or Purkinje layer (PL) being composed of Purkinje cell bodies and the inner layer, or granular layer (GL), containing large Golgi cell below the Purkinje cells, with an abundance of darkly stained granule cells.

A)

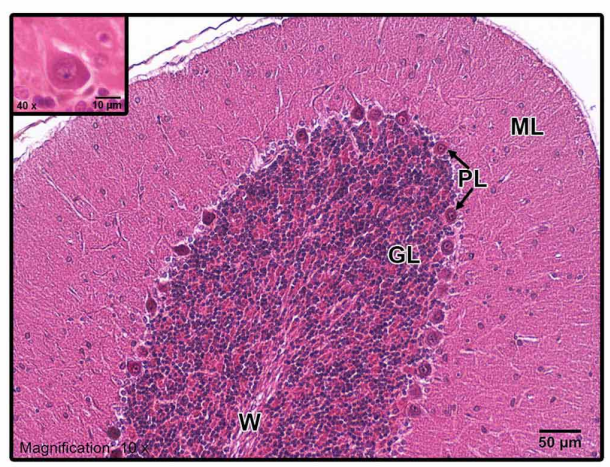

Diabetes

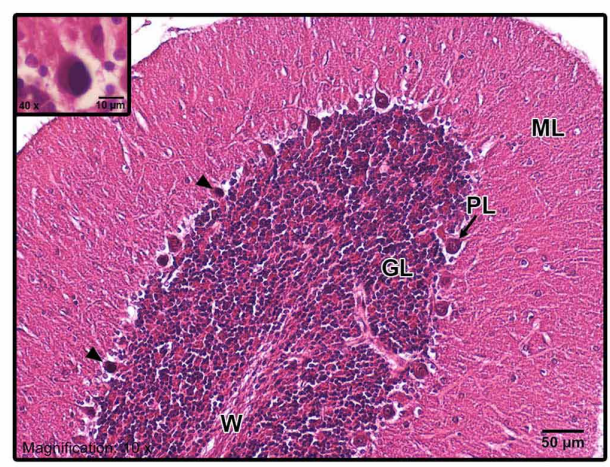

B)

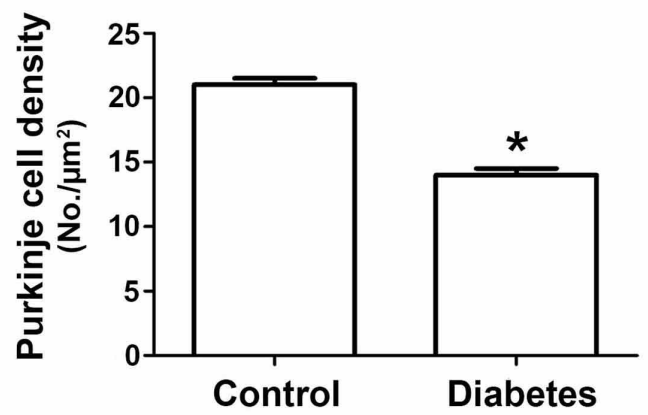

Fig. 2. Effects of diabetes on Purkinje cells. (A) Photomicrographs of the cerebellum of control and diabetic rats showing three layers of the cerebellar cortex; molecular layer (ML), Purkinje cell layer (PL), and the granular layer (GL), along with a central core of white matter (W). The diabetic cerebellum that exhibits neuropathological changes in some Purkinje cells, including shrunken cells and darkly stained nuclei (arrowheads), are clearly seen in the inset. Inset: a high magnification of the Purkinje cells, H\&E staining. (B) Quantification of Purkinje cell density per 350,000 $\mu \mathrm{m}^{2}$ area of the cerebellum, demonstrating a significantly decreased Purkinje cell count in the diabetic group. Values represent the mean \pm SEM. $\left(\mathrm{t}=9.41, \mathrm{df}=98,{ }^{*} \mathrm{p}<0.0001\right.$ compared with control $)$ 
microscopy to provide the information regarding the presynaptic area that contained the neurotransmitter vesicles, synaptic cleft, and postsynaptic area, as shown in the Figure 3A. The current study examined the numbers of synapses in the molecular layer, where the large majority synapses between the dendritic spines of Purkinje cells and climbing fibres, parallel fibres, and interneurons (stellate and basket cells) had been found. The result showed that the synapse density had decreased in the diabetic group (23.98 \pm 0.71$)$, when taken in comparison with the control group (14.00 \pm 0.55$)$ (Fig. 3B).

A

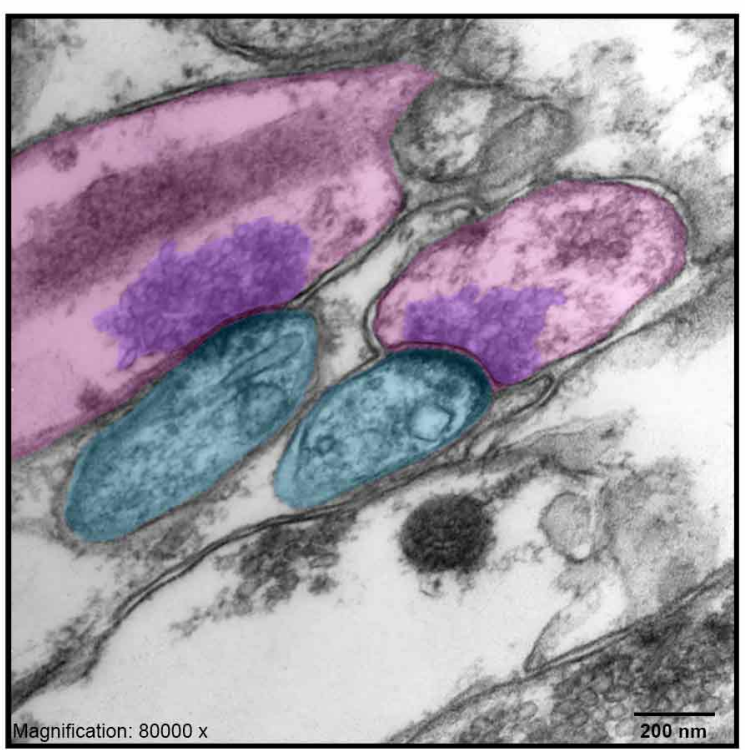

B

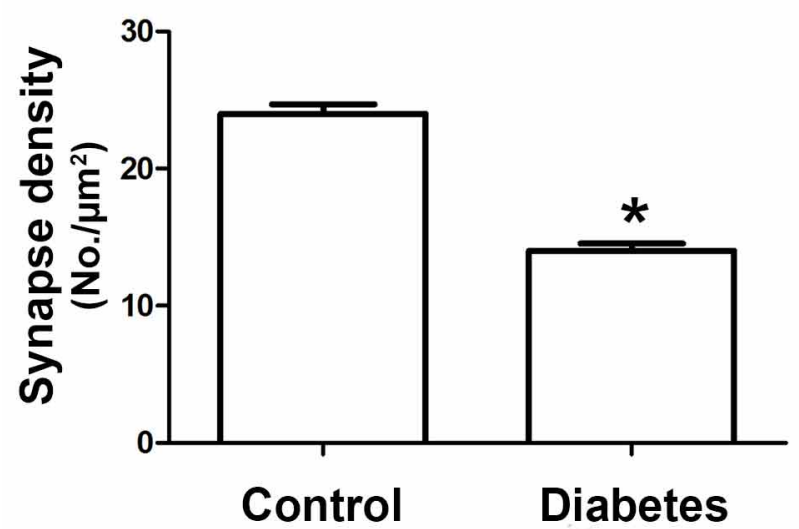

Finally, we determined the effects of diabetes on the maturation of synapses, which is one of an essential steps in the neurotransmission required for the neuronal network. Figure 3C showed a significant reduction of synapse maturation in the diabetic group (16.36 \pm 1.06$)$, when compared to control (33.88 \pm 2.27$)$. This result was associated with the dwindling density of the synaptic vesicle found in the diabetic rats. The number of synaptic vesicles decreased by approximately half when compared to that was observed in the presynaptic terminal of the control rats, as shown in the Figure 3A.

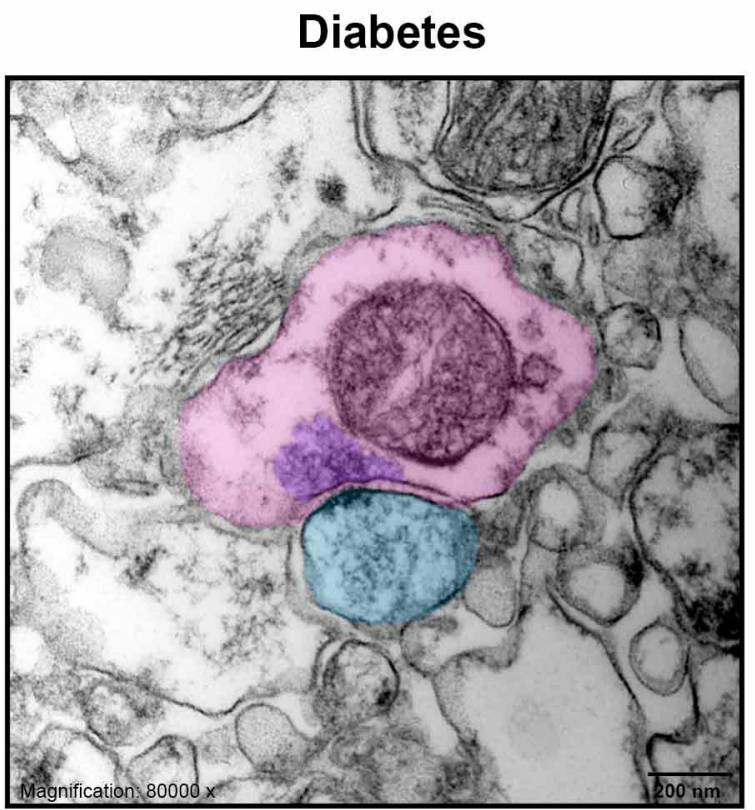

C

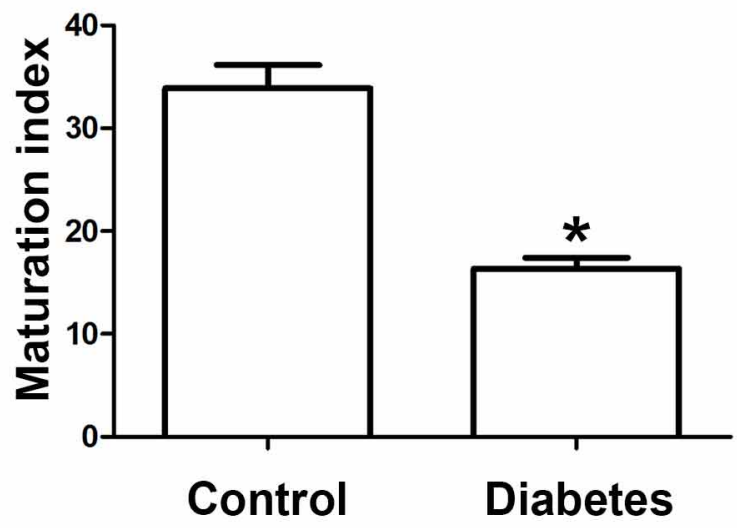

Fig. 3. Effects of diabetes on synaptopathy (A) Ultrastructural micrographs of the synaptic terminals in the cerebellar molecular layer, showing the presynaptic terminal (pink area), synaptic vesicle cluster (purple part) and postsynaptic area (blue). Diabetes demonstrated to lead to a reduced number of vesicles in the presynaptic area adjacent to the active zone. Uranyl acetate and lead citrate staining. (B) Quantitative analysis of synapse density (number per $110 \mu \mathrm{m}^{2}$ area of molecular layer) and (C) maturation index (area of clustered synaptic vesicles normalized to the area of the presynaptic terminal), illustrating a significant decrease in both synapse density $(\mathrm{t}=11.09, \mathrm{df}=98)$ and the synapse maturation $(\mathrm{t}=10.00, \mathrm{df}=98)$ of diabetes. Values represented the mean \pm SEM, * $p<0.0001$, when compared with the control. 


\section{DISCUSSION}

Diabetes mellitus, a disease that is attributed to be the direct consequences of chronic hyperglycemia, is associated with several detrimental effects on the CNS (Malone, 2016). Well-defined afferent and efferent fibre connections of the cerebellum with many important structures of the CNS is essential for its ability to coordinate the body's voluntary movements, control balance and posture, along with playing a vital role in cognition. Dysfunction of the cerebellar circuits thus presents different neuropathology of the cerebellar disorder, and based on different parts of the cerebellum, can include impairment of body balance (vestibulocerebellum), deterioration of gait (spinocerebellum), disturbance in carrying out voluntary movement (cerebrocerebellum), and cerebellar cognitive-affective syndrome (cortico-cerebellar connections between the cerebellum and prefrontal and limbic areas) (D'Angelo, 2011). The loss of synapses is viewed to be a major cause of the cerebellar circuit dysfunction. As such, this study assessed the effects of chronic diabetic condition on the synaptic profiles of rat cerebellums. Our findings showed that diabetes induces a reduction in the number of Purkinje cells, synapse density, number of synaptic vesicles, and the maturation of synapses.

Consistent with methods used in the previous reports (Nagayach et al., 2014; Razi et al.; Sherif, 2017; Solmaz et al., 2017), our study showed that the intraperitoneal administration of STZ caused a clear-cut increase in blood and urine glucose levels, with common signs of diabetes, including body weight loss, polyphagia, polydipsia and polyuria, which was due to the diabetogenic action of STZ, thus inducing the degeneration in pancreatic Langerhans islet beta cells (Akbarzadeh et al., 2007).

A significant Purkinje cell loss was also observed in the cerebellum of STZ-induced diabetic rats, as evidenced by an analysis of the significant decline in the Purkinje cell density. Cell shrinkage and pyknotic appearances that emerged in some Purkinje cells were suggestive of apoptotic cell death. Indeed, in accordance with our results, several studies had found that there were neuropathological changes of Purkinje cell which was induced by diabetes, including being smaller in size, denser cytoplasm, a darkly stained nucleus, electron-dense nuclear chromatin under the nuclear membrane, and more densely packed organelles in the cytoplasm (Hernández-Fonseca et al.; Sherif). These were apoptotic morphological features. Furthermore, the apoptotic cell death in the cerebellum, that was theorised to occur with diabetes, was confirmed by active caspase-3 immunolabeling and TUNEL assay. Extensive DNA fragmentation was found during the later stages of apoptosis, and was detected by the
TUNEL assay to be present in diabetic cerebellums (Hernández-Fonseca et al.). Intense immunolabeling of active caspase-3, an indicator of apoptosis, appeared in the three layers of diabetic cerebellar cortex, prominently in the Purkinje cells (Nagayach et al.). The major mechanism of diabetes in the cause of program cell death was hyperglycemia-mediated oxidative damage. Excessive glucose in the blood can be transported to the intracellular parts of the neuron, thus leading to the increase of neuronal glucose levels by approximately fourfold (Shah et al., 2012). High level of glucose in the cell stimulated increased oxidative stress through auto-oxidation of high intracellular glucose, along with unstable glycation, activation of the polyol pathway, and endogenous antioxidant depletion (Brownlee, 2005). The generation of excessive free radicals contributed to increased neuronal death by the oxidisation of proteins, damaging of DNA, and activation of the cellular membrane lipid peroxidation (Matough et al., 2012). Since insulin and insulin growth factors transmitted signal downstream to regulate neuronal survival (Duarte et al.), a reduction in these growth factors and their receptors was reported in the cerebellum of diabetic animals (Borges et al., 2017) and may be another possible mechanism of diabetes-induced neuronal cell death. These mechanisms are the cause of the Purkinje cell death and the decrease in numbers in the cerebellum of diabetic rat, as shown in the present study.

This study also found a lower number of cerebellar Purkinje neurons in the diabetic cerebellum, which was associated with decreased synaptic junction in the molecular layer. Purkinje cells are the sole output neurons that receive excitatory inputs from climbing fibres and parallel fibres, along with inhibitory inputs from both stellate cells and basket cells in the molecular layer. Therefore, a decrease in Purkinje cell numbers would reduce the synapse density. Moreover, the proposed effects of diabetes being able to lead to a diminishing of synaptic contacts would be considered a hyperglycemia induced downregulation of synaptophysin (SYP) protein level. SYP is an integral membrane glycoprotein of the neuronal synaptic vesicles present in all synapses, hence it has also been considered to be a specific marker of synaptic density and synapse formation. In their investigative study, Zhao et al. (2015) demonstrated that high glucose and hypoxia mimicking diabetic state in the primary neuronal culture reduces SYP protein via the promotion of the ubiquitin-proteasome system. In a study pertaining to the synaptogenesis in the cerebellum of the offspring born to diabetic mothers (Hami et al.), the expression and localization of SYP in neonates born to maternal hyperglycemia showed a reduction in all three layers of the cerebellar cortex. Furthermore, a study undertaken to probe the effect of diabetes on SYP immunoreactivity in the cerebellum of 8 week STZ-induced diabetic rat showed a 
decrease in SYP expression in the molecular layer (Sherif). Taken together, the possible mechanisms through which diabetes declined synapse formation in the cerebellar molecular layer found in the present study was from reductions of SYP expression and localisation caused by hyperglycemia.

Our ultrastructural analysis of the presynaptic morphology and vesicles supported a decrease in the number of synaptic vesicles and synapse maturation. Since the SYP protein has also been implicated in the synaptic vesicle biogenesis and release of neurotransmitters (Valtorta et al., 2004), it can be postulated that a diminished number of synaptic vesicles with reduced synapse maturation in diabetic rat cerebellum may also relate to the diabetes reduced SYP protein. Another mechanism involved as a cause for the reduced synaptic vesicle pool would be related to the increased expression of alpha-synuclein (a-Syn). This is a presynaptic protein involved in the synaptic vesicle cycle. Previous studies have been shown that an increased expression of a-Syn reduces the synaptic vesicle density at the axon terminal by inhibiting synaptic vesicle reclustering (Nemani et al., 2010). Solmaz et al. reported an accumulation of a-Syn in the cerebellar Purkinje cells of diabetic rats. A depletion of synaptic vesicles in the presynaptic mossy fibre terminals has been reported in the hippocampus of diabetic rats (Magariños \& McEwen, 2000). Thus, it is possible that the overexpression of a-Syn induced by diabetes could lead to defects in synaptic vesicle density and size, thereby resulting in the impaired maturation of the synapse.

\section{CONCLUSIONS}

In summary, the present study demonstrated that longterm diabetes could induce a decreases in 1) Purkinje cell number, 2) synapse density, 3) synaptic vesicles and 4) the maturation of synapses in the cerebellum. These findings might signify the chronic effects of diabetes on synaptopathy in the cerebellum, which could be related to cerebellar network disruption.

\section{ACKNOWLEDGEMENTS}

This study was partially supported by a Chalermprakiat Fund, Faculty of Medicine Siriraj Hospital, Mahidol University.

The authors gratefully thank to Mr. Kasem Koedpuech, Mrs. Nusara Chomanee and Mr. Mana Phongchapo for their technical assistances in light and electron microscopy.
NIYOMCHAN, A.; SRICHAROENVEJ, S.; LANLUA, P. \& BAIMAI, S. Sinaptopatía cerebelosa en ratas diabéticas inducidas por estreptozotocina. Int. J. Morphol., 37(1):28-35, 2018.

RESUMEN: Actualmente existe una creciente evidencia que apoya las complicaciones diabéticas de la estructura y función del sistema nervioso central. El cerebelo, una de las estructuras primarias del cerebro posterior, desempeña un papel importante en el control motor, la coordinación motora y las funciones no motoras, tanto como en el procesamiento cognitivo. La sinapsis es una estructura crítica que regula la comunicación neuronal y las conexiones de fibras aferentes y eferentes bien definidas en el cerebelo, ayudan a mantener el funcionamiento correcto. Por lo tanto, en el presente estudio se investigaron los efectos a largo plazo de la sinaptopatía inducida por la diabetes en el cerebelo, utilizando estudios histológicos y ultraestructurales. Veinte ratas SpragueDawley macho se dividieron al azar en grupos de control y diabetes, se indujó la diabetes a través de una inyección intraperitoneal única de estreptozotocina (60 mg / kg de peso corporal). Seis meses después, se sacrificaron las ratas y se extrajo el cerebelo. Los exámenes de microscopías óptica y electrónica mostraron una degeneración de las neuronas purkinjenses (células de Purkinje), con células reducidas, núcleos picnóticos y sinaptopatía, como también la densidad reducida de sinapsis, el número de vesículas sinápticas y la maduración de las sinapsis en la capa molecular del cerebelo de las ratas diabéticas. Las interrupciones en los perfiles sinápticos, que se observaron en la condición diabética, podrían estar relacionadas con la disfunción cerebelosa, lo que lleva a defectos en el movimiento coordinado, el equilibrio, así como al aprendizaje cognitivo y la memoria.

PALABRAS CLAVE: Cerebelo; Diabetes mellitus; Estreptozotocina; Sinaptopatía.

\section{REFERENCES}

Akbarzadeh, A.; Norouzian, D.; Mehrabi, M. R.; Jamshidi, Sh.; Farhangi, A.; Verdi, A. A.; Mofidian, S. M. \& Rad, B. L. Induction of diabetes by Streptozotocin in rats. Indian J. Clin. Biochem., 22(2):60-4, 2007.

American Diabetes Association. Diagnosis and classification of diabetes mellitus. Diabetes Care, 34(Suppl. 1):S62-9, 2011.

Borges, M. E.; Ribeiro, A. M.; Pauli, J. R.; Arantes, L. M.; Luciano, E.; de Moura, L. P.; de Almeida Leme, J. A.; Medeiros, A.; Bertolini, N. O.; Sibuya, C. Y. \& Gomes, R. J. Cerebellar Insulin/IGF-1 signaling in diabetic rats: Effects of exercise training. Neurosci. Lett., 639:157-61, 2017.

Brownlee, M. The pathobiology of diabetic complications: a unifying mechanism. Diabetes, 54(6): 1615-25, 2005.

Csajbók, É. A. \& Tamás, G. Cerebral cortex: a target and source of insulin? Diabetologia, 59(8):1609-15, 2016

D'Angelo, E. Neural circuits of the cerebellum: hypothesis for function. $J$. Integr. Neurosci., 10(3):317-52, 2011.

Duarte, A. I.; Moreira, P. I. \& Oliveira, C. R. Insulin in central nervous system: more than just a peripheral hormone. J. Aging Res., 2012:384017, 2012

Fang, P.; An, J.; Tan, X.; Zeng, L. L.; Shen, H.; Qiu, S. \& Hu, D. Changes in the cerebellar and cerebro-cerebellar circuit in type 2 diabetes. Brain Res. Bull., 130:95-100, 2017. 
Gray, S. M.; Meijer, R. I. \& Barrett, E. J. Insulin regulates brain function, but how does it get there? Diabetes, 63(12):3992-7, 2014.

Hami, J.; Vafaei-Nezhad, S.; Ivar, G.; Sadeghi, A.; Ghaemi, K.; Mostafavizadeh, M. \& Hosseini, M. Altered expression and localization of synaptophysin in developing cerebellar cortex of neonatal rats due to maternal diabetes mellitus. Metab. Brain Dis., 31(6):1369-80, 2016.

Hernández-Fonseca, J. P.; Rincón, J.; Pedreañez, A.; Viera, N.; Arcaya, J. L.; Carrizo, E. \& Mosquera, J. Structural and ultrastructural analysis of cerebral cortex, cerebellum, and hypothalamus from diabetic rats. Exp. Diabetes Res., 2009:329632, 2009.

Kleinridders, A.; Ferris, H. A.; Cai, W. \& Kahn, C. R. Insulin action in brain regulates systemic metabolism and brain function. Diabetes, 63(7):2232-43, 2014

Larsell, O. The morphogenesis and adult pattern of the lobules and fissures of the cerebellum of the white rat. J. Comp. Neurol., 97(2):281-356, 1952.

Magariños, A. M. \& McEwen, B. S. Experimental diabetes in rats causes hippocampal dendritic and synaptic reorganization and increased glucocorticoid reactivity to stress. Proc. Natl. Acad. Sci. U. S. A., 97(20):11056-61, 2000.

Malone, J. I. Diabetic central neuropathy: CNS damage related to hyperglycemia. Diabetes, 65(2):355-7, 2016.

Matough, F. A.; Budin, S. B.; Hamid, Z. A.; Alwahaibi, N. \& Mohamed, J. The role of oxidative stress and antioxidants in diabetic complications. Sultan Qaboos Univ. Med. J., 12(1):5-18, 2012.

Nagayach, A.; Patro, N. \& Patro, I. Experimentally induced diabetes causes glial activation, glutamate toxicity and cellular damage leading to changes in motor function. Front. Cell Neurosci., 8:355, 2014.

Nemani, V. M.; Lu, W.; Berge, V.; Nakamura, K.; Onoa, B.; Lee, M. K.; Chaudhry, F. A.; Nicoll, R. A. \& Edwards, R. H. Increased expression of alpha-synuclein reduces neurotransmitter release by inhibiting synaptic vesicle reclustering after endocytosis. Neuron, 65(1):66-79, 2010.

Razi, E. M.; Ghafari, S. \& Golalipour, M. J. Effect of gestational diabetes on Purkinje and granule cells distribution of the rat cerebellum in 21 and 28 days of postnatal life. Basic Clin. Neurosci., 6(1):6-13, 2015.

Shah, K.; Desilva, S. \& Abbruscato, T. The role of glucose transporters in brain disease: diabetes and Alzheimer's Disease. Int. J. Mol. Sci., 13(10):12629-55, 2012.

Sherif, R.N. Effect of cerebrolysin on the cerebellum of diabetic rats: An imunohistochemical study. Tissue Cell, 49(6):726-33, 2017.

Solmaz, V.; Köse Özlece, H.; Eroglu, H. A.; Aktug, H.; Erbas O. \& Taskıran, D. Accumulation of a-synuclein in cerebellar purkinje cells of diabetic rats and its potential relationship with inflammation and oxidative stress markers. Neurol. Res. Int., 2017:5952149, 2017.

Tedesco, A. M.; Chiricozzi, F. R.; Clausi, S.; Lupo, M.; Molinari, M. \& Leggio, M. G. The cerebellar cognitive profile. Brain, 134(Pt. 12):367286, 2011.

Valtorta, F.; Pennuto, M.; Bonanomi, D. \& Benfenati, F. Synaptophysin: leading actor or walk-on role in synaptic vesicle exocytosis? Bioessays, 26(4):445-53, 2004.

Zhao, Y.; Li, Q.; Jin, A.; Cui, M. \& Liu, X. E3 ubiquitin ligase Siah-1 downregulates synaptophysin expression under highglucose and hypoxia. Am. J. Transl. Res., 7(1):15-27, 2015.

\author{
Corresponding author: \\ Apichaya Niyomchan \\ Department of Anatomy \\ Faculty of Medicine Siriraj Hospital \\ Mahidol University \\ Bangkok \\ THAILAND
}

Email: apichaya.niy@mahidol.ac.th

Received: 07-08-2018

Accepted: 16-10-2018 